\title{
Border Procedure on Asylum and Return: Closing the Control Gap by Restricting Access to Protection?
}

\author{
Jens Vedsted-Hansen"
}

\section{Introduction}

One of the novelties in the New Pact on Migration and Asylum ${ }^{1}$ is the proposal to establish a 'seamless procedure' at external borders that will be applicable to all non-EU citizens attempting to cross these borders without the requisite authorisation. In its entirety, the proposed border procedure will comprise three elements: pre-entry screening, an asylum procedure and, where applicable, a 'swift return procedure'. The overall aim of this proposal is explained by the Commission as being to 'close the gaps between external border controls and asylum and return procedures ... thereby integrating processes which are currently separate'. ${ }^{2}$

First, the pre-entry screening will be established under a separate Proposal for a Screening Regulation ${ }^{3}$ that was presented by the Commission as part of the legislative package accompanying the EU Pact. In addition, the asylum border procedure aimed at examining asylum applications and the return border procedure for carrying out return of asylum seekers whose application has been rejected in the asylum border procedure are dealt with in the Amended Proposal for an Asylum Procedure Regulation ${ }^{4}$

* Professor at Aarhus University.

1 European Commission, 'Communication on a New Pact on Migration and Asylum', $\operatorname{COM}(2020) 609$ final, 23 September 2020.

2 Ibid 4.

3 European Commission, 'Proposal for a Regulation of the European Parliament and of the Council introducing a screening of third country nationals at the external borders and amending Regulations (EC) No 767/2008, (EU) 2017/2226, (EU) 2018/1240 and (EU) 2019/817', COM(2020) 612 final, 23 September 2020.

4 European Commission, 'Amended proposal for a Regulation of the European Parliament and of the Council establishing a common procedure for international protection in the Union and repealing Directive 2013/32/EU', $\operatorname{COM}(2020) 611$ final, 23 September 2020. 
simultaneously launched in order to change the 2016 Proposal for an Asylum Procedure Regulation. ${ }^{5}$

While this chapter will primarily focus on the latter two proposals that must be seen in conjunction, the content and impact of these procedural devices should be considered in light of the Proposal for a Screening Regulation. The pre-entry screening will necessarily interact with the asylum and return procedures at external borders, as described by Lyra Jakuleviciene in her contribution to this volume. ${ }^{6}$ In that context it should be stressed from the outset that 'closing the gap' by way of stipulating an obligation on Member States to issue a return decision immediately after a decision rejecting an application for asylum, or even simultaneously in the same decision, in order to secure quick return of asylum seekers upon rejection of their application, is in and of itself clearly a useful step, as already proposed by the Commission in the 2018 Proposal for a recast Return Directive. ${ }^{7}$

Nonetheless, the problem to be analysed here is the inherent risk of undermining legal safeguards by diluting the crucial distinction between rigorous substantive examination of the application for asylum on the one hand, and channelling applicants into various types of border procedures on the basis of initial presumptions on the absence of need for international protection on the other. In this connection, linking the asylum border procedure to certain proposed criteria for accelerated examination of applications may seem to be particularly risky. The following will first present the objective and the underlying assumptions of the New Pact as far as the border procedure and its various components are concerned (sections 2 and 3). Next, specific novelties of the proposed standards on accelerated examination and admissibility decisions in the context of the asylum border procedure will be discussed (sections 4, 5 and 6) in order to draw some preliminary conclusions on the potential effects of merging the various border procedures under the New Pact and its accompanying legislative proposals (section 7).

5 European Commission, 'Proposal for a Regulation of the European Parliament and of the Council establishing a common procedure for international protection in the Union and repealing Directive 2013/32/EU', COM(2016) 467 final, 13 July 2016.

6 Lyra Jakuleviciene's chapter on pre-screening in this volume.

7 European Commission, 'Proposal for a Directive of the European Parliament and of the Council on common standards and procedures in Member States for returning illegally staying third-country nationals (recast)', $\operatorname{COM}(2018) 634$ final, 12 September 2018, Article 8(6). 


\section{Closing the Gap: Management of Mixed Migration Flows}

One of the overriding objectives of the New Pact on Migration and Asylum is to create operational instruments for tackling the migration challenges that result from the assumed tendency towards mixed migration flows. Thus, the Commission argues that the challenges have changed since the 'refugee crisis' of 2015-16 and that mixed flows of refugees and migrants have meant 'increased complexity and an intensified need for coordination and solidarity mechanisms' ${ }^{8}$ This has been elaborated upon in the Explanatory Memorandum of the Proposal for a Screening Regulation where it is stated that the arrival of third-country nationals with clear international protection needs as observed in 2015-16 has been 'partly replaced by mixed arrivals of persons'. 9 Therefore, according to the Commission, it is now important to develop a new effective process allowing for better management of mixed migration flows and, in particular, to create a tool allowing for the identification as early as possible of persons who are 'unlikely to receive protection' in the EU. Such a tool is to be built into the process of controls at external borders with a 'swift outcome as well as clear and fair rules'. The result should be that third-country nationals will access the appropriate procedure on either asylum or return, arguably 'enhancing the synergies between external border controls, asylum and return procedures'. ${ }^{10}$

The Commission's reasoning seems to be based on the underlying assumption that the protection needs of third-country nationals can be adequately identified immediately upon their arrival at the EU external border so that asylum seekers can be 'swiftly' allocated to the appropriate procedure in order to have their protection needs examined unless they are allocated to the procedure for 'effective returns' because they are not in need of protection. Indeed, the representation in the New Pact of the pre-entry screening and its linkages to the substantive examination of applications may appear somewhat circular and perhaps even distant from the realities of examining applications for international protection. In order to decipher the apparent circularity, we shall focus on the role and intended functions of the asylum border procedure which is likely to become a kind of intermediary between pre-entry screening and the return border procedure.

8 New Pact on Migration and Asylum (n 1), 3.

9 Proposal for a Screening Regulation (n 3), Explanatory Memorandum, 1.

10 Ibid, 1. 
Depending on the organisational setup and the national administrative structures, the asylum border procedure and the return border procedure might even end up de facto gradually merging with the pre-entry screening procedure. If implemented in close connection with border procedures on asylum and return, as foreseen by the Commission, ${ }^{11}$ the pre-entry screening may ultimately come to serve as a vehicle for summary decisions on the return of applicants whose cases are rejected on inadmissibility grounds, i.e. with no substantive examination of their need for protection, or for the cursory pre-examination and allocation of applications to either the normal asylum procedure or the accelerated and/or border asylum procedure. ${ }^{12}$ This expectation seems to be supported by parts of the official reasoning behind the proposed border procedure, as shall be illustrated in the following.

\section{Novelties in the Amended Proposal for an Asylum Procedure Regulation}

The asylum border procedure under Article 41 of the Amended Proposal for an Asylum Procedure Regulation shall follow the pre-entry screening procedure provided that the asylum seeker has not yet been authorised to enter the Member States' territory and does not fulfil the entry conditions of the Schengen Borders Code. ${ }^{13}$ According to Article 41(2) of the Amended Proposal, the proposed border procedure may be applied when taking decisions on (a) the admissibility of an application for international protection and (b) the merits of an application that is being examined in an accelerated examination procedure in the cases listed in Article 40(1). As discussed below, accelerated examination and inadmissibility decisions will be the main features of the proposed asylum border procedure under the New Pact.

11 New Pact on Migration and Asylum (n 1), 4.

12 Cf Jens Vedsted-Hansen, 'Admissibility, Border Procedures and Safe Country Notions' in Sergio Carrera and Andrew Geddes (eds), The EU Pact on Migration and Asylum in light of the United Nations Global Compact on Refugees. International Experiences on Containment and Mobility and their Impacts on Trust and Rights (EUI 2021), 171-73.

13 Regulation (EU) 2016/399 of 9 March 2016 of the European Parliament and of the Council on a Union Code on the rules governing the movement of persons across borders (Schengen Borders Code) (codification) [2016] OJ L77/1. 
According to the 2016 Proposal for an Asylum Procedure Regulation, the accelerated examination procedure will be mandatory. ${ }^{14}$ By contrast, allocation to the border procedure of such accelerated examinations would generally be optional under the 2016 Proposal, ${ }^{15}$ whereas this is only supposed to be the point of departure under the corresponding provisions of the 2020 Amended Proposal. ${ }^{16}$ Importantly, this will be modified by the Amended Proposal which stipulates that the asylum border procedure will be mandatory for the accelerated examination of three types of cases:

- Where the applicant has misled the authorities by presenting false information or documents or by withholding relevant information or documents with respect to identity or nationality,

- Where the applicant may, for serious reasons, be considered a danger to the national security or public order of the Member States, and

- Where the applicant holds a nationality or has a country of former habitual residence for which the proportion of decisions granting international protection is $20 \%$ or lower. ${ }^{17}$

The latter provision refers to the Amended Proposal for an Asylum Procedure Regulation which lays down a new acceleration ground in addition to those included in the 2016 Proposal. ${ }^{18}$ Notably, this additional acceleration ground may in practice become subject to significant amplification, beyond the mandatory border procedure, by a derogation clause in the Proposal for a Crisis Regulation according to which Member States will have the option to apply the crisis border procedure to persons coming from third countries for which the EU-wide average recognition rate is above $20 \%$, but lower than $75 \% .{ }^{19}$ While the special crisis management proposal shall not be examined here, the new ground for acceleration in the Amended Proposal for an Asylum Procedure Regulation, as well as the provision concerning an EU common list of 'safe countries of origin'

14 Proposal for an Asylum Procedure Regulation (n 5), Article 40(1).

15 Ibid, Article 41(1) and (5).

16 Amended Proposal for an Asylum Procedure Regulation (n 4), Article 41(1) and (2).

17 Ibid, Article 41(3), taken together with Article 40(1)(c), (f) and (i) of the Proposal for an Asylum Procedure Regulation, as amended (see n 18).

18 Article 40(1)(i), as proposed by Amended Proposal for an Asylum Procedure Regulation (n 4), no. 14.

19 European Commission, 'Proposal for a Regulation of the European Parliament and of the Council addressing situations of crisis and force majeure in the field of migration and asylum', $\operatorname{COM}(2020) 613$ final, 23 September 2020, recital 14 and Article 4(1)(a). 
included in the 2016 Proposal as an acceleration ground, shall be further discussed below in section 4 .

As another novelty in the Amended Proposal, the obligation to examine the three types of cases mentioned above in a border procedure may be dispensed with for nationals of or stateless persons habitually resident in third countries for which a Member State has submitted a notification to the Commission that it is confronted with substantial and persisting practical problems in the cooperation on the readmission of irregular migrants, in accordance with Article $25 \mathrm{a}(3)$ of the Visa Code. ${ }^{20}$ Where the Commission upon examination considers that the third country is cooperating sufficiently, the Member State shall again apply the border procedure under the mandatory rule. ${ }^{21}$ This clearly reflects the interlinkage between the asylum border procedure and the overall policies for the management of the EU's external borders.

\section{Expanding the Criteria for Accelerated Examination of Asylum Applications}

The 2016 Proposal for an Asylum Procedure Regulation implied the introduction of accelerated examination of asylum applications on the basis of the designation of 'safe countries of origin' at EU level, as initially proposed by the Commission in a separate legislative initiative during the peak of the asylum crisis in 2015.22 The proposed EU common list of safe countries of origin includes Albania, Bosnia and Herzegovina, Northern Macedonia, Kosovo, Montenegro, Serbia and Turkey. ${ }^{23}$ Among these countries some may seem rather uncontroversial in terms of the general situation relating to human rights and the rule of law. On the other hand, considering Turkey as a 'safe country of origin' seems highly disputable given the Turkish government's overall record along these parameters, not least due to its reactions to the attempted military coup d'état two days after the proposal had been presented in July 2016.

20 Regulation (EC) No 810/2009 of 13 July 2009 of the European Parliament and of the Council establishing a Community Code on Visas (Visa Code) [2009] OJ L243/1.

21 Amended Proposal for an Asylum Procedure Regulation (n 4), Article 41(4).

22 European Commission, 'Proposal for a Regulation of the European Parliament and of the Council establishing an EU common list of safe countries of origin for the purposes of Directive 2013/32/EU', $\operatorname{COM(2015)} 452$ final, 9 September 2015.

23 Proposal for an Asylum Procedure Regulation (n 5), Article 48 and Annex 1. 
Against this background it is somewhat surprising that the Commission has not updated or qualified the reasoning of the 2016 Proposal as regards the human rights conditions in Turkey. ${ }^{24}$ The Amended Proposal for an Asylum Procedure Regulation neither modifies the provision on designation of safe countries of origin at EU level nor explicitly addresses whether and how the unmodified EU common list can be considered compatible with fundamental rights. The very notion of a common list of 'safe countries of origin' may therefore be subject to debate in connection with the negotiations of the legislative package accompanying the EU Pact.

Importantly, the Amended Proposal introduces an additional ground for accelerating the examination procedure: the applicant's nationality or, in the case of stateless persons, former habitual residence in a third country for which the proportion of decisions granting international protection is $20 \%$ or lower, according to the latest available yearly average Eurostat data. It is stipulated that exceptions are to be made (1) in situations where a 'significant change' has occurred in the third country concerned since the publication of the relevant data and (2) where the applicant belongs to a category of persons for whom the proportion of $20 \%$ or lower 'cannot be considered as representative for their protection needs' ${ }^{25}$

For one thing, the second exception may seem to constitute a contradiction insofar as it is difficult to reconcile with the rationale of accelerated procedures, apart from narrowly defined situations in which clear-cut categories of persons with a prima facie need for international protection are beyond dispute. ${ }^{26}$ If taken at surface value and implemented accordingly, the proposed exceptions further call into question the very rationale of the new acceleration ground. More generally, the need for this provision does not appear evident in the light of the already existing grounds for accelerated examination and those previously proposed, among which several are based on similar considerations of presumed safety or otherwise undeserving cases. ${ }^{27}$

24 Ibid, recital 62, cf the Proposal for a Common List Regulation (n 22), Explanatory Memorandum, 6.

25 Amended Proposal for an Asylum Procedure Regulation (n 4), Article 40(1)(i).

26 Cf ibid, recital 39a, indicating that the second exception in the proposed Article $40(1)(i)$ refers to specific categories of persons with a 'specific persecution ground'. On the ambiguity of this criterion, see Evelien Brouwer and others, The European Commission's legislative proposals in the New Pact on Migration and Asylum, Study requested by the LIBE Committee, European Parliament (PE 697.130, Policy Department for Citizens' Rights and Constitutional Affairs, 2021), 77-78.

27 Cf Article 31(8)(a)-(j) of Directive 2013/32/EU of 26 June 2013 of the European Parliament and of the Council on common procedures for granting and with- 
The Commission presents the proposed new acceleration ground as being based on 'more objective and easy-to-use criteria' and suggests that the percentage is justified by the significant increase in the number of applications made by applicants coming from countries with a low recognition rate, lower than 20\%' and 'hence the need to put in place efficient procedures to deal with those applications, which are likely to be unfounded'. ${ }^{28}$ This may have to be seen in the light of the view that the border procedure is important as a migration management tool, held by Member States in favour of stipulating the mandatory application of the border procedure. In the view of those Member States, this procedure is particularly useful where a large share of the asylum seekers are coming from countries with a low recognition rate because the border procedure can increase the chances of successful returns directly from the external border within a short period of time after their arrival due to the stronger links between asylum and return..$^{29}$

Accordingly, the purpose of the joint asylum and return border procedure is to quickly assess 'abusive asylum requests or asylum requests made at the external border by applicants coming from third countries with a low recognition rate' in order to swiftly return those without a right to stay in the EU. ${ }^{30}$ This objective of the proposed legislation is well-explained and understandable as such, yet the question remains whether it really necessitates the new ground for acceleration of the examination procedure. Basing this on the average recognition rate, with vague and potentially complex exceptions as proposed, may well rather decelerate the examination of asylum cases if it should be compatible with the effective application of the rules defining third-country nationals in need of protection. The risk of damaging the effectiveness of these substantive rules due to the lowered quality of decisions is not likely to be minimal if the accelerated examination must take place as a mandatory part of the asylum border procedure. ${ }^{31}$

drawing international protection, [2013] OJ L180/60, and Article 40(1)(a)-(h) of the Proposal for an Asylum Procedure Regulation (n 5 ).

28 Amended Proposal for an Asylum Procedure Regulation (n 4), Explanatory Memorandum, 13-14.

29 Ibid, 9.

30 Ibid, 4.

31 Cf Brouwer and others (n 26), 78; and Galina Cornelisse and Marcelle Reneman, 'Border procedures in the Member States' in EPRS Study, Asylum procedures at the border. European Implementation Assessment (PE 654.201, European Parliamentary Research Service, 2020), 98-107. 


\section{Inadmissibility Decisions in the Border Procedure}

As mentioned above, Article 41(2) of the Amended Proposal for an Asylum Procedure Regulation stipulates that the border procedure may be applied when taking decisions on the admissibility of applications for international protection, notably termed 'inadmissibility' in contrast to the more neutral heading of the provision of the 2016 Proposal which lays down the criteria for decisions on admissibility of applications. According to this provision, an asylum application shall be rejected as inadmissible on any of the following grounds:

- A non-Member State is considered to be a first country of asylum for the applicant

- A non-Member State is considered to be a safe third country for the applicant

- The application is a subsequent application where no new elements or findings relating to the examination have arisen or have been presented by the applicant

- A spouse or partner or accompanied minor lodges an application after he or she had consented to having an application lodged on his or her behalf and no facts justify a separate application. ${ }^{32}$

If an application is rejected as inadmissible in accordance with these criteria, it shall not be examined on its merits. The same applies in cases that are dealt with under the Dublin Regulation (or its successor instrument) and when another Member State has granted international protection to the applicant. ${ }^{33}$

Among these inadmissibility grounds we shall focus on the 'safe third country' rule proposed in Article 36(1)(b) of the Asylum Procedure Regulation since this is often considered the most controversial ground for inadmissibility, and possibly the most relevant in practice. This is so partly due to its vague definition, partly because of the serious consequences it is apt to have for the access to protection of those asylum seekers whose application will be rejected as inadmissible, and hence without examination by any Member State of their protection needs. According to Article 36, such rejection will be mandatory, and decisions to that effect may be taken in the asylum border procedure under the optional provision in Article 41(2) of the Amended Proposal for an Asylum Procedure Regulation.

32 Proposal for an Asylum Procedure Regulation (n 5), Article 36(1)(a)-(d).

33 Ibid, Article 36(2). 
The requirements for declaring an application inadmissible without any examination in substance are based on the presumption that the third country in question is generally 'safe' for asylum seekers and refugees. The existing admissibility rule in the Asylum Procedures Directive contains fairly modest criteria for applying the 'safe third country' notion, requiring that there is no risk of persecution or serious harm in the country, no risk of indirect refoulement from the country, and that the possibility exists to request refugee status and, if found to be a refugee, to receive protection in accordance with the Refugee Convention. ${ }^{34}$ The inadmissibility criteria in the 2016 Proposal for an Asylum Procedure Regulation are even more vague as the latter requirement will be modified to the effect that the possibility must exist to receive protection in accordance with the 'substantive standards' of the Refugee Convention or 'sufficient protection' (Article $45(1)) .35$

The proposed modification of the criteria seems likely to expand the scope for defining third countries as 'safe' and thus rejecting applications as inadmissible and returning asylum seekers to such countries in order to request protection there. The amended reference to the Refugee Convention may seem to modify the currently existing requirement that the third country provides protection in full accordance with the Convention, even if not formally bound by the Convention under international law, ${ }^{36}$ insofar as the additional criterion 'substantive standards' may be supposed to have the potential of softening the link to certain standards of protection under the Convention. Thus, in the light of recent experience it would not be surprising to see returns to 'safe third countries' where the legal or factual basis for assuming effective protection in accordance with the Refugee Convention would seem questionable. ${ }^{37}$

34 Asylum Procedures Directive (n 27), Article 38(1)(a)-(e).

35 Proposal for an Asylum Procedure Regulation (n 5), Article 45(1)(e), referring to the proposed Article 44(2) on the concept of first country of asylum as regards the term 'sufficient protection'.

36 See Jens Vedsted-Hansen, 'Asylum Procedures Directive 2013/32/EU' in Daniel Thym and Kay Hailbronner (eds), EU Immigration and Asylum Law. Article-by-Article Commentary ( $3^{\text {rd }}$ edn, C.H. Beck/Hart/Nomos 2022), Article 38 MN 3.

37 The EU arrangements with Turkey are probably the prime example. On legal aspects of the 'EU-Turkey statement' of 18 March 2016, see Thomas Spijkerboer, 'Bifurcation of people, bifurcation of law: externalization of migration policy before the EU Court of Justice' (2017) 31(2) Journal of Refugee Studies 216; and Koen Lenaerts, 'The Court of Justice of the European Union and the Refugee Crisis' in Koen Lenaerts and others (eds), An Ever-Changing Union? Perspectives on the Future of EU Law in Honour of Allan Rosas (Hart 2019), 3, 10. 
Not least importantly, the impact of the 'sufficient protection' criterion is hard to predict. One could therefore imagine future scenarios in which the proposed more flexible standard for assessing the 'sufficiency' of protection in a third country could facilitate rejecting applications as inadmissible and returning asylum seekers to that country without examining them on their merits, based on the rather abstract presumption that they can receive protection there. The proposed rules on designation of safe third countries at EU level, in addition to the designation at national level for a transitional period of five years,$^{38}$ do not seem to mitigate that concern.

The effects of the amended inadmissibility criteria under the Proposal for an Asylum Procedure Regulation will depend entirely on the actual possibility to rebut the presumption of safety and the application in practice of the requirement of an individual connection to the 'safe third country' in question. ${ }^{39}$ As to the latter, it is to be noted that the Proposal will lower the required connection threshold by including transit through a third country which is 'geographically close' to the applicant's country of origin. ${ }^{40}$ To the extent that admissibility decisions will be made in an asylum border procedure that is closely connected to, if not de facto merging with, the pre-entry screening as discussed above, such rebuttal and challenge against the application of the 'safe third country' concept may become difficult in practice.

\section{Appeal and Suspensive Effect in the Asylum Border Procedure}

An important procedural safeguard in order to enable applicants to effectively rebut the presumption of safety in a third country - whether it is considered a 'safe third country' for the purpose of inadmissibility or a 'safe country of origin' as a basis for accelerated examination on the merits - is the right to appeal and in particular the right to suspensive effect of such appeal. Although the details of the proposed rules on the right to an effective remedy and to suspensive effect fall beyond the scope of this

38 Proposal for an Asylum Procedure Regulation (n 5), Articles 46 and 50, respectively.

39 Ibid, Article 45(3) and (4).

40 Ibid, Article 45(3)(a). Under Article 38(2)(a) of the Asylum Procedures Directive (n 27) mere transit cannot constitute a 'connection' for the purpose of inadmissibility of the application, cf CJEU, FMS and Others, Joined Cases C-924/19 PPU and C-925/19 PPU, ECLI:EU:C:2020:367, paras 156-60. 
chapter, it should be highlighted that they may raise concern as regards certain cases that will be decided in the asylum border procedure.

According to Article 54 of the Amended Proposal for an Asylum Procedure Regulation, the applicant shall not have the right to remain, as will be the main rule for appellants, where the competent authority has rejected an application as unfounded or manifestly unfounded if any of the circumstances justifying the accelerated examination of the application apply, or in the cases subject to the border procedure. ${ }^{41}$ There will indeed be the possibility for appellants to request the court or tribunal seized to issue a decision on interim measures, allowing for the right to remain pending the outcome of the appeal. ${ }^{42}$ Nonetheless, due to the strict time limits and the totality of the circumstances and logistic constraints likely to prevail in the context of the border procedure, the possibility of obtaining suspensive effect under these rules may become rather illusory.

\section{Merging Border Procedures? Preliminary Conclusions}

As pointed out by Lyra Jakuleviciene, it is particularly striking that the Proposal for a Screening Regulation will eliminate the fine line that exists in international and EU law between persons seeking international protection and other migrants, following the legal rationale that persons seeking protection are subject to special treatment with regard to entry and stay in the host country during the examination of their application. In contrast to that legal distinction, the proposed pre-entry screening arguably builds on the premise that asylum seekers and migrants are the same category of unauthorised entrants and disregards the fact that asylum seekers' need for protection overrides the normal entry requirements. ${ }^{43}$

Indeed, both the Asylum Procedures Directive and the 2016 Proposal for an Asylum Procedure Regulation stipulate that asylum seekers shall have access to the examination procedure as well as the right to remain in the territory for the sole purpose of the procedure, regardless of compliance with the ordinary entry requirements under the Schengen Borders

41 Amended Proposal for an Asylum Procedure Regulation (n 4), Article 54(3)(a), cf Article 40(1) and (5) and Article 41.

42 Ibid, Article 54(4) and (5).

43 Lyra Jakuleviciene's chapter on pre-screening in this volume. 
Code. ${ }^{44}$ While this right will in principle remain under the Amended Proposal for an Asylum Procedure Regulation, some of the procedural devices here introduced may jeopardise the effective exercise of the right of access and the right to remain during the examination of the request for protection.

This risk might seem particularly real to the extent that the asylum border procedure will in practice merge or overlap with, or have blurred boundaries toward, the pre-entry screening procedure and the return border procedure. If this happens, there may be a serious risk of deviating from crucial procedural safeguards for asylum seekers and further undermining the effective application of the substantive EU rules on qualification of refugees and other third-country nationals in need of protection. As experienced at the borders of certain Member States, and illustrated by a recent study, ${ }^{45}$ the conduct of asylum procedures in the border context, including in transit zones, entails significant risks of subverting the EU asylum acquis. A further consequence of the proposed emphasis on pre-entry screening and asylum and return border procedure has been described as the multiplication of 'anomalous zones' for migration management that may ultimately become closed centres or 'border camps' amounting at least to de facto detention. ${ }^{46}$ The ongoing revision of the EU rules on asylum procedures is bound to take proper account of the existing evidence on the realities of such procedures when conducted in the various border contexts.

44 Cf Asylum Procedures Directive (n 27) recitals 25, 26, 28, 29 and Articles 6 and 9; and Proposal for an Asylum Procedure Regulation (n 5) recitals 12, 17, 22, 27 and Article 9.

45 Cf Cornelisse and Reneman (n 31).

46 Guiseppe Campesi, 'The EU Pact on Migration and Asylum and the Dangerous Multiplication of 'Anomalous Zones' for Migration Management' in Sergio Carrera and Andrew Geddes (eds), The EU Pact on Migration and Asylum in light of the United Nations Global Compact on Refugees. International Experiences on Containment and Mobility and their Impacts on Trust and Rights (EUI 2021), 195. 
